OPEN ACCESS

Edited by:

Glenn Adams,

University of Kansas, United States

Reviewed by:

Anjali Dutt,

University of Cincinnati, United States Tugce Kurtis,

University of West Georgia,

United States

*Correspondence:

Marloes A. Huis

m.a.huis@rug.nl

Specialty section:

This article was submitted to

Cultural Psychology,

a section of the journal

Frontiers in Psychology

Received: 29 May 2017 Accepted: 12 September 2017

Published: 28 September 2017

Citation:

Huis MA, Hansen N, Otten S and Lensink R (2017)

A Three-Dimensional Model

of Women's Empowerment: Implications in the Field

of Microfinance and Future Directions.

Front. Psychol. 8:1678.

doi: 10.3389/fpsyg.2017.01678

\section{A Three-Dimensional Model of Women's Empowerment: Implications in the Field of Microfinance and Future Directions}

\author{
Marloes A. Huis ${ }^{1 *}$, Nina Hansen ${ }^{1}$, Sabine Otten ${ }^{1}$ and Robert Lensink ${ }^{2,3}$ \\ ${ }^{1}$ Department of Social Psychology, University of Groningen, Groningen, Netherlands, ${ }^{2}$ Department of Economics, \\ Econometrics, and Finance, University of Groningen, Groningen, Netherlands, ${ }^{3}$ Development Economics Group, \\ Wageningen University, Wageningen, Netherlands
}

Women's empowerment is an important goal in achieving sustainable development worldwide. Offering access to microfinance services to women is one way to increase women's empowerment. However, empirical evidence provides mixed results with respect to its effectiveness. We reviewed previous research on the impact of microfinance services on different aspects of women's empowerment. We propose a Three-Dimensional Model of Women's Empowerment to integrate previous findings and to gain a deeper understanding of women's empowerment in the field of microfinance services. This model proposes that women's empowerment can take place on three distinct dimensions: (1) the micro-level, referring to an individuals' personal beliefs as well as actions, where personal empowerment can be observed (2) the meso-level, referring to beliefs as well as actions in relation to relevant others, where relational empowerment can be observed and (3) the macro-level, referring to outcomes in the broader, societal context where societal empowerment can be observed. Importantly, we propose that time and culture are important factors that influence women's empowerment. We suggest that the time lag between an intervention and its evaluation may influence when empowerment effects on the different dimensions occur and that the type of intervention influences the sequence in which the three dimensions can be observed. We suggest that cultures may differ with respect to which components of empowerment are considered indicators of empowerment and how women's position in society may influence the development of women's empowerment. We propose that a Three-Dimensional Model of Women's Empowerment should guide future programs in designing, implementing, and evaluating their interventions. As such our analysis offers two main practical implications. First, based on the model we suggest that future research should differentiate between the three dimensions of women's empowerment to increase our understanding of women's empowerment and to facilitate comparisons of results across studies and cultures. Second, we suggest that program designers should specify how an intervention should stimulate which dimension(s) of women's empowerment. We hope that this model inspires longitudinal and cross-cultural research to examine the development of women's empowerment on the personal, relational, and societal dimension.

Keywords: empowerment, agency, efficacy, gender relations, women, microfinance, culture 


\section{INTRODUCTION}

Throughout history and across nations still today, men on average have greater access to power (e.g., Brown, 1991; United Nations Development Programme [UNDP], 2015). The gender power model (Pratto and Walker, 2004; Pratto et al., 2011) suggests that power is gendered. Specifically, men relative to women have greater access to the use of force, greater access to resource control, less social obligations to uphold, and more advantageous cultural ideologies. This gender inequality can be observed in several aspects of daily life such as access to education, job opportunities, and economic resources (United Nations Development Programme [UNDP], 2015). According to a report by the United Nations Educational Scientific and Cultural Organization [UNESCO] (2014), in 2011 only $20 \%$ of the low-income nations had achieved gender parity in primary education and $66 \%$ of the world's 774 million illiterate adults were still women. There is consensus that gender equity is an important goal to be achieved (e.g., UN Women, 2011). More precisely, world leaders have agreed on working toward providing women and girls with equal access to various domains of social life (United Nations, n.d.). Diverse interventions have been developed and implemented to strengthen the position of women across the world such as health, educational or financial programs (for an overview see, UN Women, 2016). The concept of empowerment has been developed as a framework and process aimed toward addressing the inequity.

Empowerment is a process, from being unpowered to being empowered. Theorizing of empowerment stresses two main perspectives on this process: namely one more individualistic, namely through women's individual capacities and free exercise of personal choice (e.g., Kabeer, 1999) and one more collectivistic, namely through collective behavior and the adherence to cultural norms which emphasize collective growth (e.g., Budgeon, 2015, Kurtiş et al., 2016). Microfinance interventions are based on the assumption that participation in the intervention have empowering effects and stimulate individual growth. However, these interventions are often implemented in more traditional collectivistic cultures. Thus, it is crucial to conduct cultural sensitive research to avoid cultural biases and understand empowerment outcomes in different cultural contexts.

We provide a framework in which we propose that women's empowerment can be differentiated in three different dimensions, namely personal, relational (with respect to relevant others such as spouse, family, and community), and societal (at the larger social context) empowerment. We conducted our analysis in the field microfinance services as it offers a large body of empirical studies based on literature from different disciplines, mainly psychology, developmental economics, and sociology, in three steps. First, based on the reviewed literature we define women's empowerment. Second, we review empirical findings based on the three dimensions of women's empowerment to illustrate how it has been investigated so far in the context of microfinance services across cultures. Third, we integrate these three dimensions in a Three-Dimensional Model of Women's Empowerment to improve our understanding of what women's empowerment entails and how microfinance services may help to increase it.

Offering microfinance services (i.e., microloans, business training, saving programs) is currently one of the most prominent means to reduce poverty and empower the disadvantaged, including women (e.g., Armendáriz and Morduch, 2010; Kulkarni, 2011). The underlying assumption is that market participation will have liberating and empowering effects on women. This neoliberal ideology has been criticized because it neglects to acknowledge local knowledge and practices, and may even reproduce forms of oppression by extending (white) men's rights to women (e.g., Mohanty, 1995; Roodman, 2011; Bateman and Chang, 2012; Kurtiş et al., 2016). Moreover, systematic reviews on the impact of access to microcredit programs on women's empowerment have provided inconclusive results (e.g., Van Rooyen et al., 2012; Duvendack et al., 2014; Vaessen et al., 2014). Besides, the controversy of microfinance services, this field of research offers a unique context to conduct our analysis.

\section{DEFINING WOMEN'S EMPOWERMENT}

In the field of development economics women's empowerment is defined as the process through which women acquire the ability to make strategic life choices in a context where this ability was previously denied to them (Kabeer, 1999). Kabeer (1999) stresses that the ability to exercise individual choice is based on three interrelated elements - resources, agency, and achievements. Resources refer to material, human, and social expectations and allocations. Agency is the ability or sense of ability to define one's goals, act upon them, and decide on their own strategic life outcomes. Achievements include a variety of outcomes ranging from improved well-being to achieving equal representation of women in politics. In other words, the underlying assumption is that women's empowerment is the process of having and using resources in an agentic manner to reach certain achievements (e.g., Kabeer, 1999; Malhotra et al., 2002; Bali Swain and Wallentin, 2009; Khan and Khan, 2016). Similarly, psychological research suggests that empowerment is a process that enables people to act on and improve issues that are important for their individual lives, their communities, and their society (e.g., Bandura, 1986; Page and Czuba, 1999; Maton, 2008; Cattaneo and Chapman, 2010). These definitions stress the expansion of women's individual capacities and a free exercise of personal choice (see Budgeon, 2015; Kurtiş et al., 2016). However, previous research has highlighted that the act of choosing does not necessarily equate progressive outcomes for women, because women's individual choices are historically and structurally conditioned (for a debate on choice feminism see Budgeon, 2015). Indeed, this focus on women's individual liberties and growth is grounded in Western Educated Industrialized Rich Democratic (WEIRD; Henrich et al., 2010) realities and may marginalize the experience of women in different societies (e.g., Carby, 1997; Kurtiş and Adams, 2015). Decolonial feminist psychology stresses the importance of being sensitive to cultural contexts, and gaining insights from (rather than 
ignoring or devaluing) the experience of women in low income countries (coined majority-world spaces in literature in this field to reflect the majority of humankind inhabiting these societies; Kağitçibaşi, 1995; Kurtiş and Adams, 2015; Kurtiş et al., 2016). In line with this perspective, a recent study (e.g., Dutt et al., 2016) focused on the conception of women's empowerment through collective rather than individual business ownership, thereby adhering to relevant cultural norms emphasizing collective rather than individual growth (Kurtiş et al., 2016). In the definition of women's empowerment the collective is also considered. Stromquist (1995) described empowerment as a multifaceted concept including different components ranging from women's understanding of the causes of their suppression to acting collectively as a group toward social change. The work builds upon the assumption that participation in small groups with a collective agenda is the first step toward women's empowerment. Individual and collective agency are thus crucial in the development of women's empowerment (Stromquist, 2015).

Importantly, research so far has studied a variety of very different components of women's empowerment. Indeed, empirical research has investigated women's empowerment with measures such as agency, autonomy, capacity for action, self-determination, and self-confidence (e.g., Cheston and Kuhn, 2001; Malhotra et al., 2002; Narayan, 2005; Hansen, 2015). However, all definitions stress that women's empowerment is a multifaceted concept, which includes different components and assumes that empowerment is a process from being un-empowered to becoming empowered. Combining these views, we propose that empowerment is a multifaceted process, which involves individual as well as collective awareness, beliefs, and behavior embedded in the social structure of specific cultural contexts. In the current paper, we next review empirical research in the context of microfinance services to understand (1) which specific components of women's empowerment are assessed and (2) differentiate those components in personal, relational, and societal empowerment.

\section{WOMEN'S EMPOWERMENT IN THE CONTEXT OF MICROFINANCE SERVICES}

There is a large body of research on impacts of microfinance services on economic outcomes (for reviews see Banerjee et al., 2015). In the current paper, we have selected research conducted in diverse cultural contexts that has specifically focused on women's empowerment as an outcome. Previous research reports mixed evidence for the impact of access to microfinance services on women's empowerment (e.g., Duvendack et al., 2014). The diversity of reported findings may in part be explained by two main methodological differences in the studied interventions. First, microfinance programs greatly differ in their offered services (Armendáriz and Morduch, 2010). Studies report the impacts of a group lending versus individual microcredit programs (e.g., Attanasio et al., 2013) ${ }^{1}$, the impact of training programs differing in content and length (e.g., Kim et al., 2007), or microfinance interventions which may include training, saving activities, and micro loans (e.g., Hansen, 2015). Second, the study designs differ and include results from nationwide demographic survey data (e.g., Banerjee et al., 2015), randomized control trials (e.g., Tarozzi et al., 2015), behavioral games (e.g., Bulte et al., 2016), or semi-structured in-depth interviews (e.g., Sanyal, 2009) $)^{2}$. Together, these two main methodological differences make it difficult to systematically compare results and are important to keep in mind (for a review paper see Duvendack et al., 2014).

To integrate the findings of previous research, and to gain a deeper understanding of women's empowerment in the field of microfinance services, we propose a Three-Dimensional Model of Women's Empowerment. This model assumes that women's empowerment can be differentiated at three distinct dimensions: (1) the micro-level dimension, referring to individuals' personal beliefs as well as actions where personal empowerment can be observed, (2) the meso-level dimension, referring to beliefs as well as actions in relation to relevant others where relational empowerment can be observed, and finally (3) the macro-level dimension, referring to outcomes in the broader, societal context where societal empowerment can be observed. In the context of women's empowerment, capturing women's self-confidence would be located at the micro level, women feeling and acting confident in relation to their partner or social network would be a meso-level outcome, and women's situation in society would be located at the macro level.

Importantly, our aim is not to provide a full literature review, but an overview of different operationalizations of empowerment. We categorize different operationalizations into personal, relational, and societal empowerment to illustrate the importance of differentiating between these three dimensions. More precisely, we selected studies assessing commonly used quantitative and qualitative measures of women's empowerment on the personal dimension, the relational dimension, and at a broader societal dimension (see Table $\mathbf{1}$ for an overview of the discussed measures).

\section{Personal Empowerment}

Previous research has assessed the impact of access to microfinance services on different components of women's beliefs about their personal strength. Specifically, it has examined selfesteem (e.g., Stromquist, 1995; Basargekar, 2009; Kato and Kratzer, 2013), control beliefs (e.g., Morgan and Coombes, 2013; Hansen, 2015), self-confidence (Burra et al., 2005; Kim et al., 2007), and self-efficacy (e.g., Kato and Kratzer, 2013).

\footnotetext{
${ }^{1}$ We focus on the different dimensions on which women's empowerment can be measured, not the different levels on which interventions can operate. However, we note that microfinance initiatives targeting individual women compared to initiatives targeting women's groups may yield different outcomes in terms of women's empowerment across all three dimensions (e.g., Dutt et al., 2016).

${ }^{2}$ The validity of some of the different measurement-techniques has been debated (e.g., self- report; Cook and Campbell, 1979). However, in the current paper we aim to offer an overview of the different measures used to operationalize dimensions of women's empowerment and will thus not engage in this debate.
} 
TABLE 1 | Overview of reported operationalisations of women's empowerment discussed in this article.

\begin{tabular}{|c|c|c|c|}
\hline Dimension & Construct & Measures & Reference \\
\hline Personal & Locus of control & $\begin{array}{l}\text { A scale ranging from } 0 \text { (no control) to } 3 \text { (a strong personal control belief) was } \\
\text { constructed by the sum of three items (adapted from Rotter, 1966). For each }\end{array}$ & $\begin{array}{l}\text { Morgan and Coombes, } \\
\text { 2013; Hansen, } 2015\end{array}$ \\
\hline
\end{tabular}

Self confidence

Self-esteem

Self-efficacy

Relational Domestic violence

Bargaining power

Freedom of mobility

Social network size

Social capital

Collective action involvement

Societal Percentage of female microfinance borrowers

Percentage of female borrowers with school-aged children in school

Percentage female leadership in MFIs constructed by the sum of three items (adapted from Rotter, 1966). For each item participants were asked to choose between two options the one that best reflected their own belief. One option represented having control over life outcomes (e.g., 'what happens to me is my own doing') and one option representing having no control (e.g., 'sometimes / feel that I don't have enough control over the direction my life is taking').

A scale was constructed based on a positive response to at least one of two questions. Specifically, participants were asked to indicate their confidence on a scale ranging from 1 (not at all) to 5 (very much). How confident are you that you could raise your opinion in public? And, neighbors often share similar problems - how confident do you feel about offering advice to your neighbor?

Self-esteem was assessed as one of the seven indicators of self-empowerment. Participants were asked to indicate on a scale from 1 (worse than before) to 5 (very good impact) the change they'd experienced since becoming a member of the MFI. Self-esteem.

A scale ranging from 0 (no self-efficacy) to 3 (strong self-efficacy) was constructed by the sum of three scores. For each item participants were asked to indicate how many of the suggested actions they are comfortable doing. Who do you interact freely with (tick as appropriate) (a) with own family members (b) with husband's family (c) with neighbors (d) with personal friends outside family circle e) with local community leaders f) people in marketplace. At least four ticks $=1$, otherwise $=0$.

Data on violence was collected through structured interviews. Information on both physical violence (e.g., slapping, beating, kicking, etc.) and emotionally-abusive behavior (e.g., not allowing the woman to visit her natal home) was collected. Participants were asked to indicate whether any of the mentioned incidents had happened between herself and her husband in the preceding 4 months.

Bargaining power was assessed with 12 items assessing whether women were the primary decision-makers on 12 different expenditures or not. A distinction was made between total decisions (e.g., food), decisions on non-food expenditures (e.g., home purchase and repair), and decisions on loans (e.g., investment).

Participants were asked how they go to banks, markets, health centers, or places outside the village (except for their parents' place). Participants were asked to choose one of the four answer options: does not go $(=0)$, goes with husband or son $(=1)$, goes with women $(=2)$, or goes alone $(=3)$.

Participants were asked to indicate their social networks size by naming groups that they are an active member of (e.g., MFls; funeral associations; religious groups).

Data on social capital was collected through semi-structured interviews. Participants were asked to reflect on any changes - before and after group membership - in four domains, such as seeking and receiving help from others in times of personal and domestic crises.

Collective action involvement was assessed with four items assessing whether women engage in problem solving at the community level. Participants were asked to indicate whether they would act if she faces certain problems (e.g., some women being beaten up, problems with the elected chief). Next, they were asked whether they would act by themselves, with other women, or not. Data for 435 microfinance institutions was obtained from MixMarket. The percentage of female borrowers was calculated based on the total loan portfolios of the microfinance institutions.

The percentage of female borrowers with school-aged children in school was calculated by dividing the number of female borrowers with school-aged children who state that all children are in school by the total number of female borrowers with school-aged children.

Data for 329 microfinance institutions was obtained from MixMarket. The percentage of female leadership in microfinance institutions was based on three categories for female leadership: CEO, chair, and director.
2013; Hansen, 2015

Burra et al., 2005; Kim et al., 2007

Stromquist, 1995; Basargekar, 2009; Kato and Kratzer, 2013

Kato and Kratzer, 2013

e.g., Goetz and Sen Gupta, 1996; Schuler et al., 1996; Rahman, 1999; Ahmed, 2005; Naved and Persson, 2005; Bali Swain and Wallentin, 2009

e.g., Duvendack et al., 2014; Banerjee et al., 2015; Datta, 2015

Pitt et al., 2006; Bali Swain and Wallentin, 2009; Datta, 2015

Pitt et al., 2006; Sanyal, 2009; Hansen, 2015

Sanyal, 2009

e.g., Kim et al., 2007; Sanyal, 2009; Datta, 2015

e.g., Hermes et al., 2011; D’Espallier et al., 2010

Women's World Banking, 2013

Strøm et al., 2014 
TABLE 1 | Continued

\begin{tabular}{|c|c|c|c|}
\hline Dimension & Construct & Measures & Reference \\
\hline & $\begin{array}{l}\text { Percentage female staff } \\
\text { promotion and attrition }\end{array}$ & $\begin{array}{l}\text { The percentage female staff promotion and attrition was calculated by dividing } \\
\text { the number of women voluntarily leaving the institution or the number of women } \\
\text { promoted by the total number of women. }\end{array}$ & $\begin{array}{l}\text { Women's World Banking, } \\
2013\end{array}$ \\
\hline & $\begin{array}{l}\text { Average loan balance for } \\
\text { female borrowers }\end{array}$ & $\begin{array}{l}\text { The average loan balance for female borrowers was calculated by dividing } \\
\text { female borrowers' gross loan portfolio by the total number of female borrowers. }\end{array}$ & $\begin{array}{l}\text { Women's World Banking, } \\
2013\end{array}$ \\
\hline
\end{tabular}

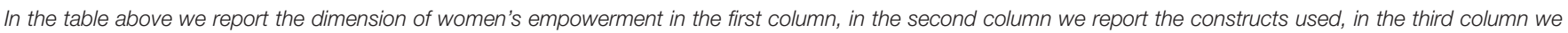
report one measure assessing this construct taken from the reference in bold, we added additional references in the fourth column.

We refer to these components as personal empowerment as they assess different psychological aspects about personal beliefs and actions. We have selected two different commonly used operationalizations, namely control beliefs (Hansen, 2015) and self-efficacy/self-esteem (Kato and Kratzer, 2013).

First, Hansen (2015) quantitatively examined the impact of a microfinance program (including skills training, saving activities, and micro loans) on psychological empowerment among women living below the poverty line in Sri Lanka. Women who had participated in the microfinance program for a period of 12-18 months were compared with a matched comparison group (no access to the program). To assess personal empowerment participants were asked to indicate their belief in their ability to control events affecting them with a self-report questionnaire (so called control beliefs, adopted from Rotter, 1966). Results indicated that women who had participated in the program reported higher levels of internal control beliefs compared to the comparison group.

Second, Kato and Kratzer $(2013)^{3}$ quantitatively and qualitatively examined the impact of membership in microfinance institutions on women's empowerment in Tanzania. Women who were members of the microfinance institutions were compared with non-members. Personal empowerment was measured with a self-report questionnaire assessing self-esteem and self-efficacy. Results indicated that women who were members of the microfinance institutions reported higher levels of self-esteem and self-efficacy than the comparison group. This result was further supported by in-depth interviews with ten members of the institutions who reported that participation in the microfinance program made them feel stronger and more respected by their families and community.

Further research in this field showed that women reported higher levels of self-esteem (e.g., Stromquist, 1995; Basargekar, 2009; Kato and Kratzer, 2013), stronger internal control beliefs (e.g., Morgan and Coombes, 2013; Hansen, 2015), and increased self-confidence (Burra et al., 2005; Kim et al., 2007). Overall, research investigating the impact of microfinance services showed mostly positive impacts for personal empowerment with respect to individual choice.

\section{Relational Empowerment}

Other research on women's empowerment has focused on women's position in relation to relevant others, such as their

\footnotetext{
${ }^{3}$ For this article we have focused on two measures reported in this article representing personal empowerment, namely self-esteem and self-efficacy.
}

partner, family, or social networks. Specifically, previous research examined the relation between access to microfinance services and women's relationships with their partner by assessing women's bargaining power within the household; the extent to which they have a say over household spending (e.g., Holvoet, 2005; Pitt et al., 2006; Duvendack et al., 2014; Upadhyay et al., 2014; Banerjee et al., 2015; Datta, 2015; Garikipati et al., 2016a), their freedom of mobility to visit places such as grocery stores or relatives outside the village (Pitt et al., 2006; Bali Swain and Wallentin, 2009; Datta, 2015) but also (risk of) intimate partner violence (e.g., Goetz and Sen Gupta, 1996; Kabeer, 1999; Rahman, 1999; Ahmed, 2005; Naved and Persson, 2005). Previous research also examined the relation between access to microfinance services and women's membership in social groups (such as microfinance groups, school groups, religious groups, women's groups) by measuring the number of social networks they are members of (e.g., Pitt et al., 2006; Sanyal, 2009; Hansen, 2015), seeking, receiving, or providing help in times of crises (e.g., Sanyal, 2009), or inclination to participate in collective action (e.g., Kim et al., 2007; Sanyal, 2009; Datta, 2015). We refer to these components as relational empowerment as they assess different aspects of women's position in relation to others. Below we will illustrate three different studies, one investigating intrahousehold decision-making power (Banerjee et al., 2015), one investigating experiences of intimate partner violence (Rahman, 1999), and one investigating women's social capital (Sanyal, 2009).

First, Banerjee et al. (2015) conducted a large-scale randomized control trial to investigate the impact of a group lending microcredit program on women's intra-household decision-making power in India. Women who had received a micro loan through their participation in the microfinance program 15-18 months ago were compared with a control group (no access to the program). To assess relational empowerment participants were asked to indicate who takes decisions about spending money on twelve different expenditures (e.g., food, education, investment). These twelve indicators of women's decision-making power were combined with four social indicators (e.g., number of female infants; enrollment of teenage girls) as a proxy for women's empowerment. Results indicated that women who had participated in the program did not show an increase in women's empowerment compared to the comparison group.

Second, Rahman (1999) set out to qualitatively examine the implications of a micro credit lending program in achieving equitable and sustainable development, including women's 
empowerment in the context of a Grameen Bank in Bangladesh (participants could apply for a micro loan). To assess relational empowerment a variety of ethnographic methods were used to assess women's experiences of intimate partner violence, and of violence by other members of the lending group and loan officers. Results indicated that a majority of female microfinance borrowers reported increased violence in the study village and increased violence and aggressive behavior (verbal aggression and physical assault) within the household because of their involvement with the bank.

Third, Sanyal (2009) conducted semi-structured in-depth interviews with female microfinance borrowers in India to examine the impact of microfinance services in promoting women's social capital and their capacity to influence social norms and practices (participants received loans). Female borrowers who were a member of one of 59 microfinance groups were selected from a stratified random sample to participate in the research. To assess relational empowerment participants were asked about their levels of agency and of social capital before and after their group membership to generate retrospective data about changes in their ability to engage in actions that they could not perform before (e.g., ability to interact with people outside the family and kinship ties, physical mobility, participation in council meetings, seeking, receiving, or providing help in times of crises). The average period of group membership was 4 years. Results indicate that women's membership in microfinance groups may improve their agency with respect to interpersonal behavior and facilitate social group membership.

Together, these studies suggest that microfinance services have mixed results regarding relational empowerment. Other research also showed mixed results, ranging from no effects to positive and even negative effects. For example, women, who participated in a microfinance program, showed no increase in intra-household decision-making power (e.g., number of expenditure decisions made by women; Banerjee et al., 2015), whereas another study indicated an increase in intra-household decision-making power (e.g., Pitt et al., 2006). Furthermore, some research provided evidence that women who received access to microfinance services experienced a decrease (e.g., Schuler et al., 1996; Kabeer, 1999; Copestake et al., 2001) whereas other research reported an increase in (risk of) intimate partner violence (e.g., Goetz and Sen Gupta, 1996; Rahman, 1999; Ahmed, 2005; Naved and Persson, 2005). Finally, research examining women's engagement in social groups reported positive impacts such as larger social networks (e.g., Pitt et al., 2006; Sanyal, 2009; Hansen, 2015) and increased levels of seeking, receiving, or providing help in times of personal or domestic crises, as well as involvement in collective action (Sanyal, 2009). Overall, research investigating the impact of microfinance services showed mixed impacts for relational empowerment.

\section{Societal Empowerment}

To the best of our knowledge, women's empowerment in the societal dimension has so far been assessed with indices that map gender gaps in human development across nations such as the Gender Development Index or specific components such as the percentage of parliamentary seats held by women. In the context of microfinance, macro-economic analyses provide insights in for example the percentage of female microfinance borrowers (e.g., D’Espallier et al., 2010; Hermes et al., 2011), female clients with school aged children in school (e.g., Women's World Banking, 2013), female leadership in microfinance institutes (e.g., Strøm et al., 2014), female staff promotion and attrition (Women's World Banking, 2013), average loan balance for female borrowers, and financial literacy services offered to women (e.g., Women's World Banking, 2013). Important to note, these studies focus on industry level indices of empowerment and do not relate to the societal level. In other words, they do not assess the impact of access to microfinance services on women's empowerment in society but rather the impact of the mere presence of women in the context of microfinance services. We will illustrate this research with two different studies.

First, Hermes et al. (2011) examined the relationship between efficiency of microfinance institutions and outreach to the poor based on data from 435 microfinance institutes. Percentage of female microfinance borrowers was used as an indicator of outreach. On average across different loan types, 58\% of the microfinance borrowers were female. The results indicate that there is a trade-off between outreach to women and efficiency of microfinance institutions. More precisely, the data suggests that microfinance institutes focusing more on female borrowers are less efficient with respect to financial performance by microfinance institutes. Second, D'Espallier et al. (2010) examined whether the percentage of female clients was related to repayment performance based on data from 350 microfinance institutions in 70 countries. The relationship between female clients and female gender bias in lending policies and indicators of repayment behavior (portfolio at risk, loan loss write-offs, and provisions) was examined. On average across different loan types, $73 \%$ of the microfinance borrowers were female. Results indicate that microfinance institutes with higher proportions of female borrowers have lower portfolio at risk and lower write-off rates indicating better repayment performance.

To conclude, these reported macro-economic effects of women's empowerment offer insight in cross-country comparisons on gender performance of microfinance institutions and possible relations between gender performance and financial performance by the microfinance institutions. Previous research examining these relations shows mixed results. For example, the percentage of (poor) female microfinance borrowers was positively (e.g., Hulme and Mosley, 1996; D’Espallier et al., 2010; Quayes, 2015; Abdullah and Quayes, 2016), negatively (e.g., Cull et al., 2007; Hermes et al., 2011), or not (e.g., D'Espallier et al., 2010) related to increased financial performance by microfinance institutions. However, while the indicators used in this type of research (e.g., percentage female borrowers, percentage female staff) provide insight in the gender outreach and/or gender effectiveness of different microfinance institutions it does not highlight the position of the female microfinance borrowers themselves.

Thus, previous research in the field of microfinance has not yet operationalized women's empowerment on the societal level as we suggest in this article. Using the mere presence of women in microfinance institutions as an indicator of women's 
empowerment is too narrow (e.g., Geleta, 2013). The research mentioned above also illustrates the complexity and potential problems in grouping diverse groups of women together to investigate the outcomes of women's empowerment. This approach may ultimately lead to a top-down way of discerning women's empowerment. To gain a deeper understanding of women's empowerment on the societal dimension, research should assess women's position in society in two ways. Indeed, research should both examine women's position by analyzing objective information about women's social conditions (i.e., status) as well as, most importantly, examine women's position relative to men (i.e., situation; for a similar argument see Johnston, 1985). We refer to women's position at a broader societal dimension as societal empowerment. Thus, we suggest that future research should follow female microfinance borrowers over time to investigate how they achieve more opportunities and rights (e.g., voting; Johnston, 1985; Beteta, 2006; education; Dijkstra, 2002). Additionally, future research should investigate how women can use these gains effectively to improve women's interests at large. For example, by striving toward improvements in women's position for future generations, such as more strongly supporting their daughters to successfully attend schooling (e.g., Kabeer, 1999; Banerjee et al., 2015), and follow different career trajectories.

\section{THREE-DIMENSIONAL WOMEN'S EMPOWERMENT MODEL}

We offer a framework suggesting that women's empowerment can occur at three distinct but related dimensions: the personal, relational, and societal dimension. Based on our review of previous research we find different effects of access to microfinance for each of the three dimensions of women's empowerment. With the risk of oversimplifying this complex matter, we suggest that the review shows first, that access to microfinance services was associated with higher levels of personal empowerment, such as increased personal control beliefs (e.g., Hansen, 2015). Second, female microfinance borrowers showed higher levels of relational empowerment on the level of social group memberships, such as larger social networks (e.g., Pitt et al., 2006). However, on the level of intimate relationships we found mixed results, showing for example both increased as well as decreased decision-making power by female borrowers (e.g., Banerjee et al., 2015). Third, with respect to societal empowerment, a positive signal is that the percentage of female borrowers receiving microfinance services is relatively high; but research provided mixed results about women's financial performance, showing positive as well as negative relations between outreach to female borrowers and financial performance by microfinance institutions (e.g., Hermes et al., 2011). Important to note, research so far has not tapped into our understanding of societal empowerment as women's situation relative to men in a broader societal dimension.

Our Three-Dimensional Women's Empowerment Model borrows the assumption from the ecological systems theory (Bronfenbrenner, 1994) that people do not exist in a social vacuum but encounter different environments throughout their life that may influence their behavior. The ecological system theory, focusing on the development of children, proposes that individuals directly influence their own experiences and vice versa within specific microsystems (e.g., family, school) and between different microsystems (mesosystems). People's development can also be influenced by settings that the individual is not directly part of (i.e., exosystem: e.g., schoolpolicy). Bronfenbrenner (1994) argues that these three lower-order systems combined, constitute consistencies fitting with relevant cultural ideologies. Next, this cultural macrosystem is influenced by time, such that the past influences the present. Our Three-Dimensional Model of Women's Empowerment broadly adheres to the same general structure and underscores the importance of the interplay between individuals and their environment.

Additionally, our proposed three-dimensional model concurs with other research noting the importance of considering changes at the individual, the relational, and the communal level when examining processes related to social change for women (e.g., Kabeer, 1999; Grabe, 2012). Importantly, our model closely ties into the empowerment process described by Rowlands (1997) in the context of social work and education. Rowlands stressed that women's empowerment occurs at three levels the personal, close relationships, and collective - and that these three levels have to be taken into account simultaneously when trying to investigate empowerment. We agree with Rowlands' claim and propose that full women's empowerment entails all three dimensions of empowerment. However, different from Rowlands we suggest that it is possible to promote and examine empowerment at each dimensions of empowerment independently, depending on one's research focus and the context in which it is embedded. In fact, we stress that women's empowerment effects on multiple dimensions need to be differentiated and not combined. While it is common practice in program evaluations to use women's empowerment indices that aggregate result from several indicators across key areas (e.g., Women's empowerment in Agriculture Index, Alkire et al., 2013), we fear that these aggregates don't do justice to the different dimensions at which empowerment can be observed.

Most importantly, we stress that one should clearly specify on which dimension of empowerment an intervention focuses to offer more systematic insights in women's empowerment across studies. If research would only focus on the personal dimension of women's empowerment (e.g., self-esteem, personal control beliefs) and use these insights to directly conclude that access to microfinance services strengthens women's empowerment within her social environment, this could provide a skewed insight and may have undesired policy implications. More specifically, when operationalizing women's empowerment in terms of women's personal control beliefs it is possible that women feel personally more in control ('I know what I am doing'), but not in relation to their partner ('My partner gets aggressive if I try to have a say in important decision-making'). In fact, previous research suggests that women's increased autonomy resulting from her participation in microfinance services can destabilize the relationship between the female 
microfinance borrower and her husband and thereby increase the risk of intimate partner violence (e.g., Goetz and Sen Gupta, 1996). This may explain the mixed results presented at different dimensions of women's empowerment (i.e., personal and relational) and illustrates the importance of carefully and explicitly choosing different aspects of women's empowerment and defining at which dimension(s) an intervention may have impacts. In the following, we discuss two aspects that influence the development of women's empowerment, namely time and culture.

\section{The Role of Time in Women's Empowerment}

Women's empowerment is seen as a process rather than a fixed outcome (e.g., Bandura, 1986; Kabeer, 1999; Malhotra et al., 2002; Maton, 2008) and described as the development from being un-empowered to becoming empowered (e.g., Kabeer, 1999; Bali Swain and Wallentin, 2009). As such, already the definition of women's empowerment underscores the importance of time in understanding its development. However, we know surprisingly little on how women's empowerment may develop over time. The proposed ThreeDimensional Women's Empowerment Model may deepen our understanding of the development of women's empowerment by disentangling the different dimensions where empowerment can be observed. However, we can only speculate about the order in which the three dimensions might develop. Moreover, we stress that the relation between access to interventions and the development of women's empowerment on the personal, relational, and societal dimension may be time-dependent.

First, if we consider the example of training offered in the context of microfinance services and thus the bottom-up development of women's empowerment, we may expect personal empowerment to develop within a relatively short time-span. Training in itself may increase people's self-efficacy and control beliefs, because people can experience their ability to perform certain tasks and increase their beliefs in their capabilities through training (Bandura, 1997). Yet, changing relational dynamics may take more time (e.g., Inglehart and Norris, 2003). Empowerment on this dimension is dependent upon other actors and may require more structural transformations (e.g., Dixon et al., 2012). Therefore, we suggest to only consider any impact of interventions on relational empowerment over a longer time-span of at least a few years. Lastly, societal empowerment is not likely to be instigated by any single intervention as it is highly related to cultural norms and traditions. Nonetheless, we suggest that societal empowerment could possibly develop over time, though it may be that this dimension of empowerment can only be observed after years (e.g., the new generation), which makes it complex to draw any conclusions about directionality or even causality. Thus, we expect that time may determine whether or not any result can be expected and observed on each of the three dimensions of women's empowerment. Also, other research argued that the time path of a program should be considered in the timing of evaluations (e.g., King and Behrman, 2009; Bonilla et al., 2017). To better understand whether effects take time to materialize or whether effects that emerge quickly persist one should measure outcomes longitudinally (McKenzie and Woodruff, 2014).

Second, we propose that the three dimensions are related but that the directionality of the model is not fixed. Even though some sequences may be more probable then other, we stress that women's empowerment can be instigated at any of the three dimensions or at multiple dimensions simultaneously. In the context of microfinance services, we suggest that women's empowerment may be a bottom-up process instigated on the personal dimension (i.e., through increased personal agency by contributing to the household income), which may then instigate the experience of empowerment on the relational and/or societal dimension. In line with this suggestion, previous psychological research conducted in the context of microfinance services stressed that women should first become aware of the options that they are individually capable of taking - i.e., their personal capacity - before they can actually proceed to influence aspects that are important to them in their daily life (Hansen, 2015). Similarly, political scientists examining the cross-cultural development of gender equity argue that women must experience personal change before relational power distributions can change (Inglehart and Norris, 2003).

In the context of microfinance services, women's empowerment may thus be seen as a process typically starting with personal empowerment and resulting in empowerment at all three dimensions, with societal empowerment as the final aspect to develop (for a similar argument see Kabeer, 2005). We recognize that this proposed sequence between personal and relational dimensions is based upon an understanding of individuals as independent agents of choice. However, women's empowerment might also be instigated on the relational dimension (i.e., small collectives; Stromquist, 1995). Nonetheless we expect societal empowerment to develop last because societal power is deeply rooted in social systems and values. It is therefore unlikely that any single intervention will completely alter power and gender relations (e.g., Cheston and Kuhn, 2001). Other authors similarly argue that gender inequity within societies may ensure that increased intra-household decision-making power (relational empowerment) will not result in structural societal changes (e.g., Johnson, 2005; Guérin et al., 2015). However, the changes instigated on the personal and relational dimension through access to microfinance services might over time also contribute to women's empowerment on the societal dimension. Empowerment on the societal dimension may then best be compared with gradual social change where cultural characteristics such as norms and values change (Pinquart and Silbereisen, 2004; de la Sablonniere, 2017), which can bring about both cultural gains (i.e., more gender equity) and losses (i.e., less social belonging; Greenfield, 2016).

Importantly, such bottom-up development of women's empowerment is not the only option. One example for a topdown approach to stimulate women's empowerment starting on 
the societal dimension is setting gender quotas (e.g., percentage of leadership positions reserved for women). Such an approach in politics aims to increase women's presence in legislature and to improve gender-related policy outcomes such as inheritance rights (e.g., Htun and Jones, 2002). This example illustrates one other possible direction in the process of women's empowerment in which an intervention is implemented at the societal level and should result in empowerment in the other two dimensions.

In sum, we suggest that time is crucial in predicting empowerment effects. First, the model suggests that the time lag between an intervention and its evaluation may influence when empowerment effects on the different dimensions are likely to be found Second, the model suggests that the three dimensions are related but that the sequence in which they can be observed depends on the implemented type of intervention.

\section{The Role of Culture in Women's Empowerment}

In the current article we discussed studies conducted in a variety of different cultural contexts, such as Sri Lanka, Bangladesh, and Tanzania. Obviously, there are important differences between these cultures. Culture can be defined as the dynamic patterns of ideas, practices, institutions, products, and artifacts that are shared by certain groups of people (Markus and Kitayama, 2010). While individual differences between people from the same cultural background are omnipresent, people within the same culture tend to hold similar values, beliefs, and practices (e.g., Smith et al., 2013). Across cultures, people may thus for example differ in how they construe their self-concept (independent or interdependent; Markus and Kitayama, 1991), to what extent they tolerate deviant behavior, and how strongly they adhere to social norms (tight or loose cultures; Gelfand et al., 2011). It may be crucial to consider these social norms in understanding and stimulating social change (Tankard and Paluck, 2016).

As highlighted in previous research, gender relations vary both geographically and over time and therefore should always be investigated in specific contexts and pertain to realities of women's lives rather than being based on a generalized assumption that they are oppressed (Mosedale, 2005; Haase, 2011; Kurtiş and Adams, 2015). Indeed, due to the diversity in interventions and cultural differences, access to microfinance cannot be expected to have one single consistent impact story (Garikipati et al., 2016b). Instead, previous research underscores the importance of considering factors such as cultural norms and attitudes in the development of women's empowerment (e.g., Johnston, 1985; Mayoux, 1999; Armendáriz and Morduch, 2010; Sardenberg, 2010). In fact, it has been stressed that empowerment develops through the interaction between the individual and the cultural context (e.g., Narayan, 2005) and that failure to consider socio-political and cultural structures can reinforce existing power imbalances (e.g., Dutt et al., 2016). Below we discuss how culture influences the meaning of women's empowerment.

First, previous research suggests that often-used indicators of women's empowerment reflect an understanding of women's empowerment based on culturally specific practices (e.g., female seclusion in South Asia) that may not apply to other cultures (e.g., Heckert and Fabric, 2013; Duvendack and PalmerJones, 2017). In line with this assumption, qualitative research conducted in Guatemala concluded that local women from five communities in Chimaltenango and Quetzaltenango did not feel empowered by having sole autonomy and decisionmaking power within the household but rather sought the involvement of their husbands (Carter, 2002). A similar conclusion was drawn based on narratives of Bangladeshi and Afghan women who chose quite different pathways of change, shaped by culturally unique norms, values and institutions, in seeking a greater degree of agency in their own lives (Kabeer, 2012). While for the interviewed Afghan women awareness of different realities experienced through migration and different regimes influenced personal empowerment, for the interviewed Bangladeshi women personal empowerment translated into greater awareness of rights and willingness to fight for them on a societal level. Moreover, how people experience each of the three dimensions of empowerment may differ based on diverse understandings of the self and the society across cultures. In cultural contexts where the social world is perceived as a dense network of connections, characterized by obligations for care and support (Kurtiş et al., 2016), women's experience of personal empowerment may be more relational than in cultural contexts where the social world is perceived as more independent. For example, research examining the impact of women's business ownership on women's empowerment among Maasai women in Tanzania showed that cooperative business ownership was more strongly related to women's empowerment than individual business ownership (Dutt et al., 2016). The authors suggest that the cooperative business ownership was more successful because it adhered to local cultural norms of social relations by emphasizing the community rather than the individual (Dutt et al., 2016; Kurtiş et al., 2016).

Indeed, psychological scholars highlight the necessity to draw upon local understandings to resonate with local realities and better serve local communities (Adams et al., 2015). Since women in local communities are best aware of what women's empowerment means to them, it may thus be crucial to allow them to set their own agenda in matters related to enhancing their own sense of empowerment (Stromquist, 1995; Kurtiş et al., 2016). Hence, members of local communities should be involved to facilitate culturally relevant social change without marginalizing women's voices (Dutt et al., 2016). While the potential lack of generalizability and tendency to overlook problematic indigenous practices may need to be considered (Adams et al., 2015), this strategy allows us to not only offer culturally adapted interventions but also reconsider often-used concepts (e.g., Comaroff and Comaroff, 2012). As argued in previous research, access to microfinance services may only empower women if cultural 
norms and expectations are taken into account (e.g., Geleta, 2013). In line with this theorizing, we expect that cultures influence how women's empowerment is defined, which aspects are important, and which components reflect women's empowerment on each of the three dimensions. Accordingly, we expect that one intervention can have diverse impacts on each of the three dimensions of women's empowerment in different cultural contexts. For example, an intervention through which women gain more economic independence might only increase women's likelihood of leaving their partner in societies where divorced women are not seen as social outcasts.

Second, women's empowerment is considered as a process wherein women challenge existing norms and culture of the society in which they live (Bali Swain and Wallentin, 2009). Accordingly, it is crucial to be aware of the cultural context and the position of women in it. Previous research highlighted that culturally defined norms and practices should be considered for a transition away from classic patriarchy to develop (Kandiyoti, 1988). Some form of patriarchy is prevalent across almost all cultures (e.g., Stockard and Johnson, 1992). However, psychological research indicated that cultures differ in the extent to which they value gender equity (e.g., Hofstede et al., 2010) and the extent to which certain gender roles are subscribed to (e.g., McCrae et al., 2005). Importantly, these gendered norms and beliefs may mediate the relation between structural equity and female suppression (Archer, 2006). Indeed, previous research reported a link between adhering to patriarchal values and sexual violence against women (e.g., Yodanis, 2004). In countries where women held a weaker position in society men more frequently showed physical aggression toward women relative to the frequency with which women showed physical aggression toward men (Archer, 2006).

In sum, the prevalence of gender inequity may obstruct possible structural societal changes resulting from access to microfinance services (e.g., Guérin et al., 2015). Empirical evidence supports this assumption. Indeed previous research analyzing the impact of fifteen different programs in Africa reports that women's empowerment depends on inflexible, household- and region-specific, social norms, and traditions (Mayoux, 1999). Similar conclusions were drawn based on a five-country study in Asia, which indicated that gender norms strongly influence the extent to which women experience empowerment (Oppenheim Mason and Smith, 2003). Thus, we propose that it is important to understand the cultural context and the position of women in society to understand the development of women's empowerment.

To conclude, we suggest that cultures may differ with respect to which components of empowerment are appropriate indicators of empowerment. Moreover, we suggest that the cultural context should be considered to properly understand the development of women's empowerment. Accordingly, when developing interventions, cultural norms should be identified and described when presenting impacts, thereby facilitating comparison between studies. To investigate at what time access to an intervention impacts women's empowerment at each of the three different dimensions across cultures, we encourage future longitudinal and crosscultural research to examine the development of women's empowerment on the personal, relational, and societal dimension.

\section{IMPLICATIONS AND FUTURE PERSPECTIVES: TOWARD A BETTER UNDERSTANDING OF WOMEN'S EMPOWERMENT}

In this paper, we aimed to increase our understanding of women's empowerment and how it should be studied in future research. We can derive four main conclusions based on our work: First, women's empowerment might best be conceptualized as a multifaceted process, which involves individual as well as collective awareness, beliefs, and behavior embedded in the social structure of specific cultural contexts. Second, based on the research reported above examining the impact of access to microfinance services on the development of women's empowerment, we concur with conclusions by previous research (e.g., Duvendack et al., 2014; Vaessen et al., 2014) that inconclusive results exist on the relation between microfinance and women's empowerment. Previous research has suggested that existing misconceptions over the potential gender effects of microfinance stem from a simplistic vision of the complex process that is empowerment (e.g., Garikipati et al., 2016b). This is in line with our third conclusion: the impact of access to microfinance services on the development of women's empowerment is hard to assess, because it is difficult to properly compare results across studies. However, if we differentiate between the three dimensions of empowerment specified in the Three-Dimensional Model of Women's Empowerment such comparisons may be improved and more consistent patterns of findings may emerge. Fourth, two crucial moderators of women's empowerment, time and culture, should be considered to increase our understanding of women's empowerment and its development.

Most of the work discussed in this paper operationalized empowerment based on an understanding of women as individual agents of change. However, including empowerment measures acknowledging the importance of vicarious others in women's experiences of empowerment - focusing on the beliefs others in one's network hold about an individual versus own beliefs - may enrich our understanding of women's empowerment. Thus, concurring with the decolonial feminist perspective (e.g., Kurtiş and Adams, 2015) we suggest that future research should be sensitive to cultural contexts, and gain insights from the experience of women in majorityworld spaces. We invite future research to develop measures to assess women's empowerment based on local operationalizations and different perspectives. Moreover, we propose that by focusing on three dimensions of empowerment, our model 
offers one way to consider the relativity of context and culture in women's empowerment. By considering not only on individual dimensions of empowerment but also on relational and societal empowerment we provide a first suggestion toward an understanding of women's empowerment that also applies to cultural worlds of embedded interdependence (see Markus et al., 1997).

Importantly, we have focused on the measurement of women's empowerment in the context of microfinance services. As such, the proposed model is most strongly substantiated in this specific context. Nonetheless, we propose that the suggested differentiation between three different dimensions may also apply to different interventions, which aim to strengthen the position of women. Additionally, in accordance with previous work (e.g., Kurtiş and Adams, 2015) we propose that the need for empowerment exists across the globe and is not unique to majority-world spaces. While most of the cited research was conducted in these societies we suggest that the different dimensions of empowerment are similarly applicable to women in WEIRD (Henrich et al., 2010) settings. Additionally, just as women's empowerment can be analyzed on personal, relational, and societal dimensions, this should similarly apply to other forms of empowerment for different marginalized groups. For example, we propose that this framework could also be used to understand the impact of diversity and inclusionprograms in industry-settings (e.g., International Labour Organization, 2014). We invite future research to use this general framework in different contexts and among different target groups.

We derive two main implications from our work. First, we suggest that future research should differentiate between the three dimensions of women's empowerment specified in the Three-Dimensional Model of Women's Empowerment, thereby increasing our understanding of women's empowerment and its development and facilitating comparison of results between studies and cultures. We hope that our model encourages future research to focus more on the development of women's empowerment over time. As a result, stronger theories may develop regarding how and why certain components on each dimension of empowerment could be impacted by different interventions. Second, but related, we suggest that program designers should specify how an intervention should stimulate which dimension(s) of women's empowerment. When developing a theory of change (White, 2009), detailing how and why activities will bring about anticipated changes in the short- and in the long-term, program designers should consider the three dimensions of women's empowerment. Moreover, researchers and program designers should consider after what time they would expect specific impacts on each of the three dimensions of women's empowerment in specific cultural contexts. We propose that the choice of intervention and of cultural context has consequences for to be expected pathway through which women's empowerment may develop and be observed.

\section{CONCLUSION}

Empowering women is seen as one of the central issues in the process of sustainable development for many nations worldwide (e.g., Sen, 1999; Organization for Economic Cooperation and Development [OECD], 2012; United Nations Economic Commision for Europe [UNECE], 2012; Gates, 2015). Around the globe, governments and different organizations strive to increase women's empowerment by implementing different interventions such as offering access to microfinance services to promote sustainable development and human rights.

The Three-Dimensional Model of Women's Empowerment integrates different literatures studying the impact of offering microfinance services on women's empowerment. The core premise of the model is to differentiate between three different dimensions of women's empowerment, namely (1) personal empowerment, referring to individual's personal beliefs as well as actions, (2) relational empowerment, referring to beliefs as well as actions in relation to relevant others, and (3) societal empowerment, referring to the situation of women in the broader societal context to understand how women's empowerment may develop. Furthermore, unraveling two important moderators of empowerment, namely time and culture, the model allows a more dynamic understanding of why some women may feel more empowered than others, why some women may express higher levels of personal but not relational empowerment, and why one specific microfinance intervention may show positive impacts on women's empowerment in one but not another nation. Integrating all three dimensions of women's empowerment into one research model provides new theoretical insights into how women's empowerment may develop through access to microfinance services and offers clear practical implications for involved stakeholders in the field.

\section{AUTHOR CONTRIBUTIONS}

$\mathrm{MH}, \mathrm{NH}, \mathrm{SO}$, and RL contributed to the discussion and development of the conceptual framework of this article. $\mathrm{MH}$ and $\mathrm{NH}$ conducted the literature review, analyzed the results, and wrote the manuscript. SO contributed to the rewriting of the manuscript. All authors approved the final version of the manuscript.

\section{ACKNOWLEDGMENT}

We are grateful to Martijn van Zomeren and Julia Sasse for their valuable feedback on an earlier version of this work. 


\section{REFERENCES}

Abdullah, S., and Quayes, S. (2016). Do women borrowers augment financial performance of MFIs? Appl. Econ. 48, 5593-5604. doi: 10.1080/00036846.2016.1181831

Adams, G., Dobles, I., Gómez, L. H., Kurtiş, T., and Molina, L. E. (2015). Decolonizing psychological science: introduction to the special thematic section. J. Soc. Polit. Psychol. 3, 213-238. doi: 10.5964/jspp.v3i1.564

Ahmed, S. M. (2005). Intimate partner violence against women: experiences from a woman-focused development programme in Matlab, Bangladesh. J. Health Popul. Nutr. 23, 95-101.

Alkire, S., Meinzen-Dick, R. S., Peterman, A., Quisumbing, A. R., Seymour, G., and Vaz, A. (2013). The women's empowerment in agriculture index. World Dev. 52, 71-91. doi: 10.1016/j.worlddev.2013.06.007

Archer, J. (2006). Cross-cultural differences in physical aggression between partners: a social-role analysis. Pers. Soc. Psychol. Rev. 10, 133-153. doi: 10.1207/ s15327957pspr1002_3

Armendáriz, B., and Morduch, J. (2010). The Economics of Microfinance, 2nd Edn. Cambridge: MIT Press.

Attanasio, O. P., Augsburg, B., de Haas, R., Fitzsimons, E., and Harmgart, H. (2013). Group Lending or Individual Lending? Evidence from a Randomized Field Experiment in Rural Mongolia. CentER Discussion Paper Series No. 2013-014. Tilburg: Finance.

Bali Swain, R., and Wallentin, F. Y. (2009). Does microfinance empower women? Evidence from self-help groups in India. Int. Rev. Appl. Econ. 23, 541-556. doi: 10.1080/02692170903007540

Bandura, A. (1986). Social Foundations of Thought and Action: A Social Cognitive Theory. Englewood Cliffs, NJ: Prentice-Hall.

Bandura, A. (1997). Self-Efficacy: The Exercise of Control. New York, NY: Freeman.

Banerjee, A. V., Duflo, E., Glennerster, R., and Kinnan, C. (2015). The miracle of microfinance: evidence from a randomized evaluation. Am. Econ. J. Appl. Econ. 7, 22-53. doi: 10.1257/app.20130533

Basargekar, P. (2009). Microcredit and a macro leap: an impact analysis of Annapurna Mahila Mandal (AMM), an urban microfinance institution in India. IUP J. Financ. Econ. 7, 105-120.

Bateman, M., and Chang, H. (2012). Microfinance and the illusion of development: from hubris to nemesis in thirty years. World Econ. Rev. 1, 13-36.

Beteta, H. C. (2006). What is missing in measures of women's empowerment? J. Hum. Dev. 7, 221-241. doi: 10.1080/14649880600768553

Bonilla, J., Zarzur, R. C., Handa, S., Nowlin, C., Peterman, A., Ring, H., et al. (2017). Cash for women's empowerment? A mixed-methods evaluation of the government of Zambia's child grant program. World Dev. 95, 55-72. doi: 10.1016/j.worlddev.2017.02.017

Bronfenbrenner, U. (1994). "Ecological models of human development," in International Encyclopedia of Education, 2nd Edn, Vol. 3, eds T. Husen and T. N. Postlethwaite (Oxford: Pergamon Press), 1643-1647.

Brown, D. E. (1991). Human Universals. Philadelphia, PA: Temple University Press.

Budgeon, S. (2015). Individualized femininity and feminist politics of choice. Eur. J. Womens Stud. 22, 303-318. doi: 10.1177/135050681557 6602

Bulte, E., Lensink, B. W., and Vu, N. (2016). Gender training and female empowerment. Experimental evidence from Vietnam. Econ. Lett. 145, 117-119. doi: 10.1016/j.econlet.2016.06.003

Burra, N., Deshmukh-Ranadive, J., and Murthy, R. K. (2005). Micro-Credit, Poverty and Empowerment: Linking the Triad. New Delhi: Sage Publications.

Carby, H. (1997). "White woman listen! Black feminism and the boundaries of sisterhood," in Materialist Feminism: A Reader in Class, Difference, and Women's Lives, eds R. Hennessy and C. Ingraham (New York, NY: Routledge Kegan Paul), 110-128.

Carter, M. W. (2002). 'Because he loves me': husbands' involvement in maternal health in Guatemala. Cult. Health Sex. 4, 259-279. doi: 10.1080/ 13691050110112784

Cattaneo, B., and Chapman, A. R. (2010). The process of empowerment: a model for use in research and practice. Am. Psychol. 65, 646-659. doi: 10.1037/ a0018854

Cheston, S., and Kuhn, L. (2001). Engendering Development: Through Gender Equality in Rights, Resources, and Voice. Washington, DC: World Bank.
Comaroff, J., and Comaroff, J. L. (2012). Theory from the South: or, how EuroAmerica is evolving toward Africa. Anthropol. Forum 22, 113-131. doi: 10.1080/ 00664677.2012.694169

Cook, T. D., and Campbell, D. T. (1979). Quasi-Experimentation: Design and Analysis Issues for Field Settings. Boston, MA: Houghton Mifflin Company.

Copestake, J., Bhalotra, S., and Johnson, S. (2001). Assessing the impact of microcredit: a Zambian case study. J. Dev. Stud. 37, 81-100. doi: 10.1080/ 00220380412331322051

Cull, R., Demirguc-Kunt, A., and Morduch, J. (2007). Financial performance and outreach: a global analysis of leading microbanks. Econ. J. 117, 107-133. doi: 10.1111/j.1468-0297.2007.02017.x

Datta, U. (2015). Socio-economic impacts of JEEViKA: a large-scale self-help group project in Bihar, India. World Dev. 68, 1-18. doi: 10.1016/j.worlddev.2014. 11.013

de la Sablonniere, R. (2017). Toward a psychology of social change: a typology of social change. Front. Psychol. 8:397. doi: 10.3389/fpsyg.2017.00397

D'Espallier, B., Guérin, I., and Mersland, R. (2010). Women and repayment in microfinance: a global analysis. World Dev. 39, 758-772. doi: 10.1016/j. worlddev.2010.10.008

Dijkstra, A. G. (2002). Revisiting UNDP's GDI and GEM: towards an alternative. Soc. Indic. Res. 57, 301-338. doi: 10.1023/A:1014726207604

Dixon, J., Levine, M., Reicher, S., and Durrheim, K. (2012). Beyond prejudice: Are negative evaluations the problem? Is getting us to like one another more the solution? Behav. Brain Sci. 35, 411-425. doi: 10.1017/S0140525X11002214

Dutt, A., Grabe, S., and Castro, M. (2016). Exploring links between women's business ownership and empowerment among Maasai women in Tanzania. Anal. Soc. Issues Public Policy 16, 363-386. doi: 10.1111/asap.12091

Duvendack, M., and Palmer-Jones, R. (2017). Micro-finance, women's empowerment and fertility decline in Bangladesh: How important was women's agency? J. Dev. Stud. 53, 664-683. doi: 10.1080/00220388.2016. 1205731

Duvendack, M., Palmer-Jones, R., and Vaessen, J. (2014). Meta-analysis of the impact of microcredit on women's control over household decisions: methodological issues and substantive findings. J. Dev. Effect. 6, 73-96. doi: 10.1080/19439342.2014.903289

Garikipati, S., Agier, I., Guérin, I., and Szafarz, A. (2016a). The cost of empowerment: multiple sources of women's debt in rural India. J. Dev. Stud. 53, 700-722. doi: 10.1080/00220388.2016.1205734

Garikipati, S., Johnson, S., Guérin, I., and Szarfarz, A. (2016b). Microfinance and gender: issues, challenges and the road ahead. J. Dev. Stud. 53, 641-648. doi: 10.1080/00220388.2016.1205736

Gates, M. (2015). Valuing the health and contribution of women is central to global development. Lancet 386, 11-12. doi: 10.1016/S0140-6736(15)60940

Geleta, E. B. (2013). Microfinance and the politics of empowerment: a critical cultural perspective. J. Asian Afr. Stud. 49, 413-425. doi: 10.1177/ 0021909613487679

Gelfand, M., Raver, J., Nishii, L., Leslie, L., Lun, J., Lim, B., et al. (2011). Differences between tight and loose cultures: a 33-nation study. Science 332, 1100-1104. doi: 10.1126/science.1197754

Goetz, A. M., and Sen Gupta, R. (1996). Who takes the credit? Gender, power, and control over loan use in rural credit programs in Bangladesh. World Dev. 24, 45-63. doi: 10.1016/0305-750X(95)00124-U

Grabe, S. (2012). An empirical examination of women's empowerment and transformative change in the context of international development. Am. J. Commu. Psychol. 49, 233-245. doi: 10.1007/s10464-0119453-y

Greenfield, P. M. (2016). Social change, cultural evolution, and human development. Curr. Opin. Psychol. 8, 84-92. doi: 10.1016/j.copsyc.2015. 10.012

Guérin, I., D’Espallier, B., and Venkatasubramanian, G. (2015). The social regulation of markets: why microcredit fails to promote jobs in rural South India. Dev. Change 46, 1277-1301. doi: 10.1111/dech.2015.46.issue-6

Haase, D. (2011). Revolution, interrupted: gender and microfinance in Nicaragua. Crit. Sociol. 38, 221-240. doi: 10.1177/0896920511404443

Hansen, N. (2015). The development of psychological capacity for action: the empowering effect of a microfinance programme on women in Sri Lanka. J. Soc. Issues 71, 597-613. doi: 10.1111/josi.12130 
Heckert, J., and Fabric, M. S. (2013). Improving data concerning women's empowerment in Sub-Saharan Africa. Stud. Fam. Plan. 44, 319-344. doi: 10.1111/j.1728-4465.2013.00360.x

Henrich, J., Heine, S. J., and Norenzayan, A. (2010). The weirdest people in the world? Behav. Brain Sci. 33, 61-83. doi: 10.1017/S0140525X0999152X

Hermes, N., Lensink, R., and Meesters, A. (2011). Outreach and efficiency of microfinance institutions. World Dev. 39, 938-948. doi: 10.1016/j.worlddev. 2009.10.018

Hofstede, G., Hofstede, G. J., and Minkov, M. (2010). Cultures and Organizations: Software of the Mind, 3rd Edn. New York, NY: McGraw-Hill.

Holvoet, N. (2005). The impact of microfinance on decision-making agency: evidence from South India. Dev. Change 36, 75-102. doi: 10.1111/j.0012-155X. 2005.00403.x

Htun, M. N., and Jones, M. P. (2002). "Engendering the right to participate in decision-making: electoral quotas and women's leadership in Latin America," in Gender and the Politics of Rights and Democracy in Latin America, eds N. Craske and M. Molyneux (London: Palgrave Macmillan).

Hulme, D., and Mosley, P. (1996). Finance against Poverty. New York, NY: Routledge.

Inglehart, R., and Norris, P. (2003). Rising Tide: Gender Equality and Cultural Change Around the World. New York, NY: Cambridge University Press.

International Labour Organization (2014). Promoting Equity: Ethnic Diversity in the Workplace: A Step-by-Step Guide. Geneva: International Labour Office.

Johnson, S. (2005). Gender relations, empowerment and microcredit: moving on from a lost Decade. Eur. J. Dev. Res. 17, 224-248. doi: 10.1080/ 09578810500130831

Johnston, D. (1985). The development of social statistics and indicators on the status of women. Soc. Indic. Res. 16, 233-261. doi: 10.1007/BF00415125

Kabeer, N. (1999). Resources, agency, achievements: reflections on the measurement of women's empowerment. Dev. Change 30, 435-464. doi: $10.1111 / 1467-7660.00125$

Kabeer, N. (2005). Gender equality and women's empowerment: a critical analysis of the third millennium development goal. Gender Dev. 13, 13-24. doi: 10.1080/ 1355207051233133227

Kabeer, N. (2012). Empowerment, citizenship and gender justice: a contribution to locally grounded theories of change in women's lives. Ethics Soc. Welfare 6, 216-232. doi: 10.1080/17496535.2012.704055

Kagitçibaşi, Ç (1995). Is psychology relevant to global human development issues? Am. Psychol. 50, 293-300. doi: 10.1037/0003-066X.50.4.293

Kandiyoti, D. (1988). Bargaining with patriarchy. Gender Soc. 2, 274-290. doi: $10.1177 / 089124388002003004$

Kato, M. P., and Kratzer, J. (2013). Empowering women through microfinance: evidence from Tanzania. ACRN J. Entrep. Perspect. 2, 31-59.

Khan, S. R., and Khan, S. R. (2016). Microcredit in South Asia: privileging women's perceptions and voices. Prog. Dev. Stud. 16, 65-80. doi: 10.1177/ 1464993415608083

Kim, J. C., Watts, C., Hargreaves, J. R., Ndhlovu, L. X., Phetla, G., Morison, L. A., et al. (2007). Understanding the impact of a microfinance-based intervention on women's empowerment and the reduction of intimate partner violence in South Africa. Am. J. Public Health 97, 1794-1802. doi: 10.2105/AJPH.2006. 095521

King, E. M., and Behrman, J. R. (2009). Timing and duration of exposure in evaluations of social programs. World Bank Res. Obs. 24, 55-82. doi: 10.1093/ wbro/lkn009

Kulkarni, V. S. (2011). Women's Empowerment and Microfinance: An Asian Perspective Study. Occasional Paper International Fund for Agricultural Development (IFAD) no. 13. Available at: https:/www.ifad.org/documents/ 10180/313c7bf6-7196-4918-bff6-ea1c892cbf15

Kurtiş, T., and Adams, G. (2015). Decolonizing liberation: toward a transnational feminist psychology. J. Soc. Polit. Psychol. 3, 388-413. doi: 10.5964/jspp. v3i1.326

Kurtiş, T., Adams, G., and Estrada-Villalta, S. (2016). Decolonizing empowerment: implications for sustainable well-being. Anal. Soc. Issues Public Policy 16, 387-391. doi: 10.1111/asap.12120

Malhotra, A., Schuler, S. R., and Boender, C. (2002). Measuring Women's Empowerment as a Variable in International Development. Washington, DC: World Bank.
Markus, H. R., and Kitayama, S. (1991). Culture and the self: implications for cognition, emotion, and motivation. Psychol. Rev. 98, 224-253. doi: 10.1037/ 0033-295X.98.2.224

Markus, H. R., and Kitayama, S. (2010). Cultures and selves: a cycle of mutual constitution. Perspect. Psychol. Sci. 5, 420-430. doi: 10.1177/17456916103 75557

Markus, H. R., Mullally, R., and Kitayama, S. (1997). "Selfways: diversity in modes of cultural participation," in The Conceptual Self in Context, eds U. Neisser and D. Jopling (New York, NY: Cambridge University), 13-60.

Maton, K. I. (2008). Empowering community settings: agents of individual development, community betterment, and positive social change. Am. J. Commun. Psychol. 41, 4-21. doi: 10.1007/s10464-007-9148-6

Mayoux, L. (1999). Questioning virtuous spirals: microfinance and women's empowerment in Africa. J. Int. Dev. 11, 957-984. doi: 10.1002/(SICI)10991328(199911/12)11:7<957::AID-JID623>3.0.CO;2-\#

McCrae, R. R., Terracciano, A., and Personality Profiles of Cultures Project (2005). Universal features of personality traits from the observer's perspective: data from 50 cultures. J. Pers. Soc. Psychol. 88, 547-561. doi: 10.1037/0022-3514.88. 3.547

McKenzie, D., and Woodruff, C. (2014). What are we learning from business training and entrepreneurship evaluations around the developing world? World Bank Res. Obs. 29, 48-82. doi: 10.1093/wbro/lkt007

Mohanty, M. (1995). On the concept of empowerment. Econ. Polit. Wkly. 30, 1434-1436.

Morgan, M., and Coombes, L. (2013). Empowerment and advocacy for domestic violence victims. Soc. Personal. Psychol. Compass 7, 526-536. doi: 10.1111/spc3. 12049

Mosedale, S. (2005). Policy arena assessing women's empowerment: towards a conceptual framework. J. Int. Dev. 17, 243-257. doi: 10.1002/jid.1212

Narayan, D. (2005). Measuring Empowerment: Cross-Disciplinary Perspectives. Washington, DC: World Bank.

Naved, R. T., and Persson, L. A. (2005). Factors associated with spousal physical violence against women in Bangladesh. Stud. Fam. Plan. 36, 289-300. doi: 10.1111/j.1728-4465.2005.00071.x

Oppenheim Mason, K., and Smith, H. L. (2003). Women's Empowerment and Social Context: Results from Five Asian Countries. Washington DC: World Bank.

Organization for Economic Cooperation and Development [OECD] (2012). Gender Equality in Education, Employment and Entrepreneurship: Final Report to the MCM 2012. Available at: http://www.oecd.org/employment/50423364. pdf

Page, N., and Czuba, C. (1999). Empowerment: What is it? J. Ext. 37, 1-6.

Pinquart, M., and Silbereisen, R. K. (2004). Human development in times of social change: theoretical considerations and research needs. Int. J. Behav. Dev. 28, 289-298. doi: 10.1080/01650250344000406

Pitt, M. M., Khandker, S. R., and Cartwright, J. (2006). Empowering women with micro finance: evidence from Bangladesh. Econ. Dev. Cult. Change 54, 791-831. doi: $10.1086 / 503580$

Pratto, F., Lee, I., Tan, J., and Pitpitan, E. (2011). "Power basis theory: a psychoecological approach to power," in Social Motivationed, ed. D. Dunning (New York, NY: Psychology Press), 191-222.

Pratto, F., and Walker, A. (2004). "The bases of gendered power," in The Psychology of Gender, 2nd Edn, eds A. H. Eagly, A. Beall, and R. Sternberg (New York, NY: Guilford Publications), 242-268.

Quayes, S. (2015). Outreach and performance of microfinance institutions: a panel analysis. Appl. Econ. 47, 1909-1925. doi: 10.1080/00036846.2014.1002891

Rahman, A. (1999). Micro-credit initiatives for equitable and sustainable development: Who pays? World Dev. 27, 67-82. doi: 10.1016/S0305-750X(98) 00105-3

Roodman, D. (2011). Due Diligence: An Impertinent Inquiry into Microfinance. Washington, DC: Center for Global Development.

Rotter, J. B. (1966). Generalized expectancies for internal versus external control of reinforcement. Psychol. Monogr. 80, 1-28. doi: 10.1037/h0092976

Rowlands, J. (1997). Questioning Empowerment: Working with Women in Honduras. Oxford: Oxfam. doi: 10.3362/9780855988364

Sanyal, P. (2009). From credit to collective action: the role of microfinance in promoting women's social capital and normative influence. Am. Sociol. Rev. 74, 529-550. doi: 10.1177/000312240907400402 
Sardenberg, C. M. B. (2010). Family, households and women's empowerment in Bahia, Brazil, through the generations: Continuities or change? IDS Bull. 41, 88-96. doi: 10.1111/j.1759-5436.2010.00127.x

Schuler, S. R., Hashemi, S. M., Riley, A. P., and Akhter, S. (1996). Credit programs, patriarchy and men's violence against women in rural Bangladesh. Soc. Sci. Med. 43, 1729-1742. doi: 10.1016/S0277-9536(96)00068-8

Sen, A. K. (1999). Development as Freedom. New York, NY: Knopf Press.

Smith, P. B., Fischer, R., Vignoles, V., and Bond, M. H. (2013). Understanding Social Psychology across Cultures. Engaging with Others in a Changing World. London: SAGE.

Stockard, J., and Johnson, M. M. (1992). Sex and Gender in Society, 2nd Edn. Englewood Cliffs, NJ: Prentice-Hall.

Strøm, R. Ø., D’Espallier, B., and Mersland, R. (2014). Female leadership, performance, and governance in microfinance institutions. J. Bank. Finance 42, 60-75. doi: 10.1016/j.jbankfin.2014.01.014

Stromquist, N. P. (1995). "The theoretical and practical bases for empowerment," in Women, Education and Empowerment: Pathways towards Autonomy, ed. C. Mendel-Anonuevo (Hamburg: UNESCO Institute for Education), $13-22$.

Stromquist, N. P. (2015). Women's empowerment and education: linking knowledge to transformative action. Eur. J. Educ. 50, 307-324. doi: 10.1111/ ejed.12137

Tankard, M. E., and Paluck, E. L. (2016). Norm perception as a vehicle for social change. Soc. Issues Policy Rev. 10, 181-211. doi: 10.1111/sipr.12022

Tarozzi, A., Desai, J., and Johnson, K. (2015). The impacts of microcredit: evidence from Ethiopia. Am. Econ. J. Appl. Econ. 7, 54-89. doi: 10.1257/app.201 30475

UN Women (2011). The Women's Empowerment Principles: Equality Means Business. Available at: http://www.unwomen.org/-/media/headquarters/ attachments/sections/library/publications/2011/10/women-s-empowermentprinciples_en\%20pdf.pdf?la=en\&vs=1504

UN Women (2016). UN Women Annual Report 2015-2016. Available at: http://annualreport.unwomen.org/en/2016

United Nations Development Programme [UNDP] (2015). Human Development Report 2015. Work for Human Development. Available at: http://hdr.undp.org/ sites/default/files/2015_human_development_report.pdf

United Nations Economic Commision for Europe [UNECE] (2012). Empowering Women for Sustainable Development. Available at: https://www.unece.org/ fileadmin/DAM/Gender/publication/UNECE_Discussion_Paper_2012.1.pdf
United Nations Educational, Scientific and Cultural Organization [UNESCO] (2014). EFA Global Monitoring Report. Teaching and Learning, Achieving Quality for All. Available at: http://unesdoc.unesco.org/images/ 0022/002266/226662e.pdf

United Nations (n.d.) Sustainable Development. Gender Equality - Why It Matters. Available at: http://www.un.org/sustainabledevelopment/gender-equality/

Upadhyay, U. D., Gipson, J. D., Withers, M., Lewis, S., Ciaraldi, E. J., Fraser, A., et al. (2014). Women's empowerment and fertility: a review of the literature. Soc. Sci. Med. 115, 111-120. doi: 10.1016/j.socscimed.2014. 06.014

Vaessen, J., Rivas, A., Duvendack, M., Palmer Jones, R., and Waddington, H. (2014). The effects of microcredit on women's control over household spending in developing countries: a systematic review and meta-analysis. Campbell Syst. Rev. 8, 1-205. doi: 10.4073/csr.2014.8

Van Rooyen, C., Stewart, R., and de Wet, T. (2012). The impact of microfinance in Sub Saharan Africa: a systematic review of the evidence. World Dev. 40, 2249-2262. doi: 10.1016/j.worlddev.2012.03.012

White, H. (2009). Theory-Based Impact Evaluation: Principles and Practices. International Initiative for Impact Evaluation (3ie). Available at: www.3ieimpact. org/media/filer_public/2012/05/07/Working_Paper_3.pdf

Women's World Banking (2013). Gender Performance Indicators. How Well Are We Serving Women. Available at: http://www.womensworldbanking. org/wp content/uploads/2013/09/Womens-World-Banking-GenderPerformanceIndicators.pdf

Yodanis, C. L. (2004). Gender inequality, violence against women, and fear: a cross-national test of the feminist theory of violence against women. J. Interpers. Violence 19, 655-675. doi: 10.1177/088626050426 3868

Conflict of Interest Statement: The authors declare that the research was conducted in the absence of any commercial or financial relationships that could be construed as a potential conflict of interest.

Copyright (c) 2017 Huis, Hansen, Otten and Lensink. This is an open-access article distributed under the terms of the Creative Commons Attribution License (CC BY). The use, distribution or reproduction in other forums is permitted, provided the original author(s) or licensor are credited and that the original publication in this journal is cited, in accordance with accepted academic practice. No use, distribution or reproduction is permitted which does not comply with these terms. 